\title{
An Empirical Justification for the Use of Draft Lottery Numbers as a Random Treatment in Political Science Research
}

\author{
Adam J. Berinsky \\ Department of Political Science, Massachusetts Institute of Technology, 77 Mass Ave, E53-457, \\ Cambridge, MA 02139 \\ e-mail: berinsky@mit.edu \\ Sara Chatfield \\ Postdoctoral Associate, Department of Political Science, Massachusetts Institute of Technology, 77 \\ Mass Ave, E53-457, Cambridge, MA 02139 \\ e-mail: sarachat@mit.edu (corresponding author) \\ Edited by Justin Grimmer
}

\begin{abstract}
Over the past several years, there has been growing use of the draft lottery instrument to study political attitudes and behaviors (see, e.g., Bergan 2009; Erikson and Stoker 2011; Henderson 2012; Davenport 2015). Draft lotteries, held in the United States from 1969 to 1972, provide a potentially powerful design; in theory, they should provide true randomization for the "treatment" of military service or behavioral reactions to the threat of such service. However, the first draft lottery conducted in 1969 was not conducted in a random manner, giving those citizens born in the fourth quarter of the year disproportionately higher chances of being drafted. In this note, we describe the randomization failure and discuss how this failure could in theory compromise the use of draft lottery numbers as an instrumental variable. We then use American National Election Studies data to provide support for the conclusion that individuals most affected by the randomization failure (those born in the fourth quarter of the year) largely do not look statistically distinct from those born at other times of the year. With some caveats, researchers should be able to treat the 1969 draft numbers as if they were assigned at random. We also discuss broader lessons to draw from this example, both for scholars interested in using the draft lottery as an instrumental variable, and for researchers leveraging other instruments with randomization failures. Specifically, we suggest that scholars should pay particular attention to the sources of randomization failure, sample attrition, treatment and dependent variable selection, and possible failure of the exclusion restriction, and we outline ways in which these problems may apply to the draft lottery instrument and other natural experiments.
\end{abstract}

\section{A Brief History of the Draft}

Although the word "lottery" implies randomization, the circumstances behind any natural experiment should be carefully examined to determine whether randomization was, in fact, carried out successfully. In the case of the 1969 draft lottery, there were fundamental problems with the way in which lottery officials attempted to randomize draft numbers. On November 26, 1969, President Nixon signed an amendment to the Military Selective Service Act of 1967, which permitted the establishment of a random selection sequence for induction into the armed forces. The first lottery was held on December 1, 1969, and generated the draft order for men born between 1944 and 1950. A key feature of the lottery was that each cohort was only at risk of induction for a single year. If men were not called to service before the next lottery, they were not required to enter the military.

\footnotetext{
Authors' note: We thank Mike Sances and Seth Dickinson for helpful comments. Supplementary materials for this article are available on the Political Analysis Web site. Replication data are available at the Harvard Dataverse: see Berinsky and Chatfield (2015) at http://dx.doi.org/10.7910/DVN/4K4VTC.
} 
Additional lotteries were held in 1970 for the 1951 birth cohort, in 1971 for the 1952 birth cohort, and in 1972 for the 1953 cohort.

The first lottery was conducted in an unusual manner. As related by Fienberg (1971), each birthdate was placed into a separate capsule and then mixed together using a staggered procedure. The January capsules were added to the box first and pushed to one side, and then the February capsules were added and the box was mixed. This same process was then repeated for the remaining months, meaning that the January capsules were mixed eleven times, whereas the December capsules were mixed only once. After the capsules were mixed together, they were emptied from one side of the box into a bowl for numbers to be drawn. Once placed in the bowl, the capsules were not stirred. Because the officials who drew the capsules did so primarily from the top of the bowl, individuals with birthdays later in the year were more likely to be drawn earlier in the procedure and thus be assigned low draft numbers. Fienberg (1971) examined the average lottery number by month and found a clear trend in this distribution. Men born in November and December had, on average, particularly low lottery numbers. ${ }^{1}$

\section{The Consequences of Randomization Failure}

The failed randomization of the 1969 draft has been recognized by some political scientists (e.g., Erikson and Stoker 2011) but not others (e.g., Bergan 2009). That said, the failure to fully randomize the birthdates is not, in and of itself, necessarily problematic. As Erikson and Stoker note, this randomization failure only poses a threat to causal inference if there are systematic differences in politically relevant attributes between citizens born in different months of the year. Ultimately, here - as in any circumstance where a randomization failure has occurred - the key question for researchers is whether that failure creates systematic bias in relevant outcomes.

Recent work suggests that an individual's month of birth could, at least indirectly, affect politically relevant attributes. There is a large literature in the social and natural sciences finding that the month of a child's birth is associated with later outcomes, including health, educational attainment, and earnings (for a review, see Buckles and Hungerman 2013). Many of these studies find that children born in winter months have suboptimal outcomes; for instance, individuals born in the winter have lower educational attainment. While there are competing explanations for this effect-ranging from compulsory schooling laws (Angrist and Krueger 1991) to fertility patterns among different groups of women (Buckles and Hungerman 2013) - the season of one's birth can have effects on demographic markers later in life.

This fact is particularly important for political scientists because factors such as education and income have important political implications. Given the nonrandomness of the 1969 draft lottery, looking only at the effect of draft numbers for the cohort of citizens who were born in November and December from 1944 to 1950 might conflate the effect of draft number and season-of-birth effects. Put another way, without controls for the season of birth, researchers might incorrectly attribute season-of-birth effects to draft numbers.

\section{Data and Method}

To test whether season of birth is related to relevant characteristics, we examined pooled data from the American National Election Studies (ANES). ${ }^{2}$ Information about the respondents' precise date of birth is typically redacted for privacy reasons, but since 1968, the ANES has released birth month with its general data. ${ }^{3}$ We pooled data from 1968 to the present for two sets of individuals.

\footnotetext{
${ }^{1}$ The Selective Service System responded to the criticism of the first draft lottery by revising its procedures. The second lottery, held on July 1, 1970, was based on a simultaneous drawing from two different drums, each containing 365 capsules. The capsules in the first drum contained dates, and the capsules in the second drum contained draft-order numbers (see Fienberg 1971 for further details on the draft lottery procedure).

${ }^{2} \mathrm{~A}$ replication file is available at the Harvard Dataverse. See Berinsky and Chatfield (2015).

${ }^{3}$ It should be noted that because only month of birth is released by the ANES, we cannot assess possible confounding that could occur through the clustering of lottery assignment within months. However, due to the specific nature of the randomization failure described above, we consider this possibility to be fairly unlikely.
} 
First, we examined the full set of respondents. ${ }^{4}$ Second, we looked only at those individuals who were eligible for the 1969 draft (males born between 1944 and 1950).

We performed a series of cross-tabulations, difference-of-

means tests, and Kolmogorov-Smirnov tests of difference in distributions. ${ }^{5}$ We compared respondents born in the fourth quarter of the year (October-December) to the rest of the sample on a number of political and demographic measures contained in the ANES. These individuals are most likely to have been affected by the failed draft lottery randomization, and on average had lower draft numbers than those born at other times of the year. We examined the distributions of two types of variables: demographic variables that are highly correlated with political outcomes (education and income) and political outcomes themselves (measures of political interest, political knowledge, ideology, party identification, and political participation). We included demographic variables both because previous studies have documented significant, if small, effects of birth month on educational attainment and earnings (see Buckles and Hungerman 2013), and because these demographic variables are highly correlated with a number of political outcomes. If there are significant birth month effects on education and income in our data, we would be concerned that birth month could indirectly influence key political outcomes like knowledge, participation, or ideology. We selected the political outcomes listed above both for their relationship with education and income, and because they are of broad interest to political scientists. ${ }^{6}$

A summary of these results is presented in Tables 1 and 2. These tables compare individuals born in the fourth quarter of the year with individuals born at other times of the year, both for the full sample and for the cohort that was eligible for the 1969 draft lottery. ${ }^{7}$ These results do not suggest that fourth-quarter respondents are meaningfully distinct from those born at other times of the year. Only one of the forty hypothesis tests performed on fourth-quarter births yields significant differences, and there are no significant differences for the group of draft-eligible males.

\section{Broader Applications and Discussion}

The above analysis addresses the randomization failure of the draft lottery specifically. But, our analysis has important implications for the use of the draft lottery as an instrument and, more generally, for the use of designs involving natural experiments where randomization is imperfect.

Even though we may be able to treat draft numbers from the 1969 draft cohort as being assigned as if random, researchers should be careful when using the draft lottery as an instrumental variable. Sovey and Green (2011) summarize a number of issues that instrumental variable designs must address; in additional to randomization failures, scholars should also carefully consider the potential for heterogeneous treatment effects, sample attrition, whether the instrument satisfies the exclusion restriction (i.e., whether it could influence the dependent variable in ways other than through treatment), the strength of the instrument, the possible presence of "defiers" who intentionally seek out the inverse of their treatment condition, and the stable unit treatment value assumption (i.e., that outcomes are determined solely by one's own treatment condition and not the treatment condition of others). Sample attrition, satisfying the exclusion restriction, and selecting appropriate dependent variables are all particularly relevant to the case of the draft lottery, which we discuss further.

As Henderson (2012) addresses, sample attrition can be a serious problem because those with high versus low lottery numbers may respond to surveys at different rates. Those with low numbers may be less likely to respond because they were engaged in military conflict at the time of the

\footnotetext{
${ }^{4}$ Individuals for whom birth month or year were not available were not included in the sample. We also did not include individuals from supplemental samples who are not included in the ANES cumulative file (such as the supplemental oversample of African American voters in 1968).

${ }^{5} \mathrm{~K}-\mathrm{S}$ statistics are bootstrapped due to the large number of ties in the data.

${ }^{6} \mathrm{~A}$ full list of variables from the ANES is included in the replication file provided with this note, and should allow researchers to analyze any additional variables of interest.

${ }^{7}$ Results for first-quarter birth dates are available in an online appendix. While these individuals were not as impacted by the randomization failure, prior research indicates that this group would be more likely to experience birth-month effects.
} 
Table 1 Fourth-quarter births versus all other respondents: Full sample

\begin{tabular}{lcclcccc}
\hline \multirow{2}{*}{ Variable } & $\begin{array}{l}\text { Pearson's } \\
\text { chi-squared }\end{array}$ & p-value & $\begin{array}{l}\text { Difference- } \\
\text { in-means }\end{array}$ & p-value & K-S test & p-value & $\mathrm{N}$ \\
\hline Education (4 category) & 4.2387 & .237 & - & - & .010 & .555 & 35556 \\
Education (7 category) & 6.0217 & .421 & - & - & .010 & .558 & 35557 \\
Income & 10.1907 & $.037^{*}$ & - & - & .007 & .927 & 32567 \\
Political knowledge (Pre) & 7.3299 & .119 & - & - & .016 & .253 & 21712 \\
Political knowledge (Post) & 4.5260 & .339 & - & - & .013 & .389 & 26171 \\
Interest in campaigns & 1.9597 & .375 & - & - & .008 & .831 & 32996 \\
Party identification & 4.2197 & .647 & -.0022 & .930 & .005 & .996 & 35454 \\
Liberal/Conservative ideology & 2.4690 & .872 & -.0045 & .835 & .007 & .991 & 22463 \\
Voter registration & 3.2258 & .072 & - & - & .011 & .689 & 24356 \\
Voter participation & 3.5520 & .059 & - & - & .011 & .405 & 33082 \\
\hline
\end{tabular}

* indicates significance at the .05 level or lower.

Table 2 Fourth-quarter births versus all other respondents: Draft cohort

\begin{tabular}{llllllll}
\hline Variable & $\begin{array}{l}\text { Pearson's } \\
\text { chi-squared }\end{array}$ & p-value & $\begin{array}{l}\text { Difference- } \\
\text { in-means }\end{array}$ & p-value & K-S test & p-value & $\mathrm{N}$ \\
\hline Education (4 category) & 2.8187 & .420 & - & - & .010 & 1 & 4966 \\
Education (7 category) & 9.1652 & .164 & - & - & .025 & .626 & 4966 \\
Income & 3.2536 & .516 & - & - & .011 & .999 & 4649 \\
Political knowledge (pre) & 1.8206 & .769 & - & - & .016 & .999 & 2956 \\
Political knowledge (post) & .9166 & .922 & - & - & .008 & 1 & 3567 \\
Interest in campaigns & .4749 & .789 & - & - & .008 & 1 & 4606 \\
Party identification & 7.5761 & .271 & .1015 & .103 & .037 & .156 & 4945 \\
Liberal/Conservative ideology & 1.4784 & .961 & -.0045 & .835 & .017 & .995 & 3444 \\
Voter registration & .4727 & .492 & - & - & .010 & 1 & 3369 \\
Voter participation & .0005 & .983 & - & - & 0 & 1 & 4640 \\
\hline
\end{tabular}

survey, had long-lasting health issues, or were out of the country due to avoiding the draft. Or, they may be more likely to respond because their experiences during the war motivated an interest in political issues. Importantly, to the extent that educational and health outcomes are related to month of birth, it is possible that these factors interact with a low lottery number to create different attrition rates for those born at different times of the year.

The appropriateness of draft numbers as an instrument also may vary depending on the choice of the treatment and dependent variable(s) of interest. As Dunning (2012) notes, the lottery is likely not a good instrument for the treatment of military service, since volunteers may vary widely from draftees. Instead, the lottery may be a valid instrument for conscripted military service or, as in Erikson and Stoker (2011), the vulnerability of having a high draft number, whether or not one actually served. Importantly, whether the exclusion restriction is satisfied depends on the treatment and dependent variable(s) in a particular study. Dunning (2012) notes that Angrist's (1990) study using lottery numbers as an instrument for conscripted military service with earnings as the dependent variable may be problematic because a low lottery number could also raise earnings through an alternate mechanism, by encouraging an individual to obtain additional years of college education in efforts to avoid the draft. In contrast, a design like Erikson and Stoker's (2011) suffers less from this issue since the treatment they are interested in encompasses a wider variety of responses to a low draft number and includes various forms of draft dodging.

The choice of dependent variables is also important: for instance, studying the political attitudes of draftees themselves is more straightforward, whereas studying the political attitudes of draftees' children may present more problems. Specifically, studying the children of draftees involves a 
number of selection issues: those engaged in military conflict might be more likely to delay fatherhood, and those who had a particularly negative experience during the war (i.e., experiencing severe injuries or psychological trauma) might avoid fatherhood altogether. Ultimately, researchers should be careful to address issues of attrition and selection beyond the randomization of draft numbers themselves when considering its use as an instrument.

Turning to our second point, beyond the specific example of the U.S. draft lottery, social science scholars are frequently faced with natural experiments in which randomization is imperfect. For example, as Kreuger and Zhu (2004) note, scholars interested in leveraging randomly assigned school tuition vouchers must account for the complex and sometimes faulty randomization performed by the administrators of these policies. ${ }^{8}$ More broadly, as Dunning (2010) outlines, many studies utilize interventions that are assigned "as if" random, but scholars must carefully justify the plausibility of this determination. Our recommendation in these cases is to begin with a qualitative understanding of the precise nature of the randomization failure or the plausibility of treating a nonrandom intervention as if it were random. As in the case of the draft lottery, it is crucial to understand the conditions under which assignment to treatment and control was made, and the points at which randomization may have gone wrong. For example, in this case the way in which the lottery balls were mixed indicates that birth month could be a potential confounder, whereas other demographic variables like race do not present similar randomization concerns. Then, researchers should tailor diagnostic tests to the specific nature of the randomization failure to identify whether and to what extent that failure may introduce bias into the instrumental variable analysis.

\section{Conclusion}

The analysis presented here is reassuring for scholars wishing to take advantage of the draft lottery as an instrument in political science research. Although the key instrumental variable assumption of random assignment was violated by a faulty draft procedure in 1969, researchers can largely treat the lottery assignment as if it were random. For individuals born in the fourth quarter of the year, there is one significant difference for the full sample, and none for the 1969 draft cohort, among forty comparisons. Still, these analyses represent only one set of results, for one sample, and on one particular set of variables. When birth-month data are available, researchers may still want to include robustness tests that include measures for the respondents' quarter or month of birth. But when using data where birth month is not available, this evidence should provide reassurance that lottery numbers can be treated as if they were assigned randomly.

We hope this analysis can also be instructive to scholars interested in other natural experiments where randomization was imperfect. These results suggest that such problems do not automatically doom a research design. Instead, scholars should consider qualitative evidence about the precise nature of the randomization failure and then design balance or sensitivity tests that take into account this information. As in this case, these tests may rely on variables such as month of birth that are seemingly unrelated to political outcomes but that still have the potential to bias results.

\section{References}

Angrist, Joshua D. 1990. Lifetime earnings and the Vietnam era draft lottery: Evidence from Social Security Administration Records. American Economic Review 80(3):313-36.

Angrist, Joshua D., and Alan B Krueger. 1991. Does compulsory school attendance affect schooling and earnings? Quarterly Journal of Economics 106(4):979-1014.

Bergan, Daniel E. 2009. The draft lottery and attitudes towards the Vietnam War. Public Opinion Quarterly 73(2):379-84. Berinsky, Adam, and Sara Chatfield. 2015. Replication data for: An empirical justification for the use of draft lottery numbers as a random treatment in political science research http://dx.doi.org/10.7910/DVN/4K4VTC, Harvard Dataverse, V1.

\footnotetext{
${ }^{8}$ Kreuger and Zhu's study focuses on the New York City school voucher program, in which families (rather than students) were randomized according two different relatively complex procedures, and were sometimes incorrectly categorized into strata before randomization due to misreporting by families.
} 
Buckles, Kasey, and Daniel M. Hungerman. 2013. Season of birth and later outcomes: Old questions, new answers. Review of Economics and Statistics 95(3):711-24.

Davenport, Tiffany C. 2015. Policy-induced risk and responsive participation: The effect of a son's conscription risk on the voting behavior of his parents. American Journal of Political Science 59(1):225-241.

Dunning, Thad. 2010. Design-based inference: Beyond the pitfalls of regression analysis? In Rethinking social inquiry, eds. Henry E. Brady and David Collier. Lanham, MD: Rowman and Littlefield.

- 2012. Natural experiments in the social sciences: A design-based approach. Cambridge: Cambridge University Press.

Erikson, Robert, and Laura Stoker. 2011. Caught in the draft: The effects of Vietnam draft lottery status on political attitudes. American Political Science Review 105(2):221-37.

Fienberg, Stephen E. 1971. Randomization and social affairs: The 1970 draft lottery. Science 171(3968):255-61.

Henderson, John. 2012. Demobilizing a generation: The behavioral effects of the Vietnam draft lottery. Working paper. http://www.jahenderson.com/research [Accessed July 14, 2014].

Kreuger, Alan B., and Pei Zhu. 2004. Another look at the New York City school voucher experiment. American Behavioral Scientist 47(5):658-98.

Sovey, Allison J., and Donald P. Green. 2011. Instrumental variables estimation in political science: A reader's guide. American Journal of Political Science 55(1):188-200. 